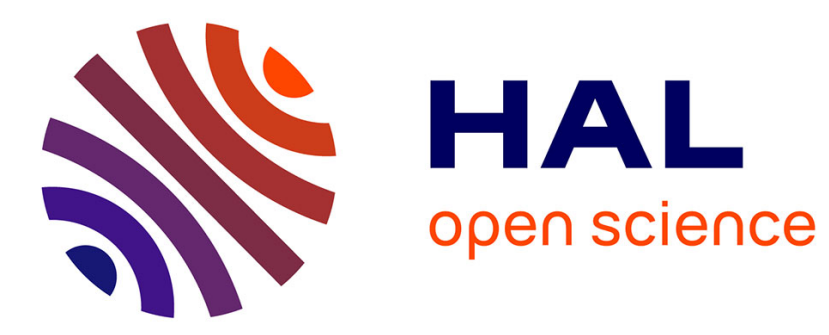

\title{
DFT Study of Tris(bis(trimethylsilyl)methyl)lanthanum and -samarium
}

David Clark, John Gordon, P. Jeffrey Hay, Richard Martin, Rinaldo Poli

\section{To cite this version:}

David Clark, John Gordon, P. Jeffrey Hay, Richard Martin, Rinaldo Poli. DFT Study of Tris(bis(trimethylsilyl)methyl)lanthanum and -samarium. Organometallics, 2002, 21 (23), pp.50005006. 10.1021/om0205061. hal-03283830

\section{HAL Id: hal-03283830 https://hal.science/hal-03283830}

Submitted on 19 Jul 2021

HAL is a multi-disciplinary open access archive for the deposit and dissemination of scientific research documents, whether they are published or not. The documents may come from teaching and research institutions in France or abroad, or from public or private research centers.
L'archive ouverte pluridisciplinaire HAL, est destinée au dépôt et à la diffusion de documents scientifiques de niveau recherche, publiés ou non, émanant des établissements d'enseignement et de recherche français ou étrangers, des laboratoires publics ou privés. 


\section{A DFT Study of Tris(bis(trimethylsilyl)methyl)lanthanum and-samarium}

David L. Clark, ${ }^{a}$ John C. Gordon, ${ }^{b}$ P. Jeffrey Hay, ${ }^{* c}$ Richard L. Martin ${ }^{\mathrm{c}}$ and Rinaldo Poli*d

${ }^{a}$ Nuclear Materials Technology Division and G. T. Seaborg Institute, Los Alamos National Laboratory, Mail Stop E500, Los Alamos, NM 87545.

${ }^{b}$ Chemistry Division, Los Alamos National Laboratory, Mail Stop J514, Los Alamos, NM 87545.

'Theoretical Division, Los Alamos National Laboratory, Mail Stop B268, Los Alamos, NM87545.

${ }^{d}$ Laboratoire de Synthèse et d'Electrosynthèse Organométalliques (LSEO UMR 5632), Université de Bourgogne, Faculté de Sciences "Gabriel”, 6 boulevard Gabriel, 21000 Dijon, France.

Proofs to:

P. Jeffrey Hay

T-12, Mail Stop B268, T-12

Los Alamos National Laboratory, Los Alamos, NM 87545

email: pjhay@lanl.gov 


\begin{abstract}
DFT calculations have been carried out on compounds $\mathrm{Ln}\left[\mathrm{CH}\left(\mathrm{SiR}_{2} \mathrm{R}^{\prime}\right)\left(\mathrm{SiR}_{3}\right)\right]_{3}$ for $\mathrm{Ln}=$ La and Sm and (i) $\mathrm{R}=\mathrm{R}^{\prime}=\mathrm{Me}$; (ii) $\mathrm{R}=\mathrm{H}, \mathrm{R}^{\prime}=\mathrm{Me}$; (iii) $\mathrm{R}=\mathrm{R}^{\prime}=\mathrm{H}$. The results are compared with the X-ray structures that are available from the literature for both metals and $\mathrm{R}=\mathrm{R}^{\prime}=\mathrm{Me}$. The calculations correctly reproduce the experimental structural features in these complexes exhibiting the peculiar pyramidal coordination geometry. The results show significant increases in the $\mathrm{Si}-\mathrm{C}$ bond lengths associated with $\beta$-Si-C agostic interactions, whereas little structural changes are found for $\gamma-\mathrm{C}-\mathrm{H}$ agostic interactions. The latter are in fact repulsive. The simplified model system with $\mathrm{R}=\mathrm{H}$ and $\mathrm{R}^{\prime}=\mathrm{Me}$ that retains one agostic methyl interaction in each alkyl ligand also correctly reproduces the essential geometrical features. The simplest model with only $\mathrm{SiH}_{3}$ groups, while also adopting a pyramidal coordination geometry, no longer accurately describes the real molecule since the $\beta$-Si-C agostic interactions are replaced by $\beta-\mathrm{Si}-\mathrm{H}$ interactions. A Mulliken analysis of the electronic structure shows a relatively covalent $\mathrm{Ln}-\mathrm{C}$ interaction with significant $5 \mathrm{~d}$ orbital participation in the bonding. A number of calculations with different basis sets on the model $\mathrm{Sm}\left[\mathrm{CH}\left(\mathrm{SiH}_{2} \mathrm{Me}\right)\left(\mathrm{SiH}_{3}\right)\right]_{3}$ system shows that the addition of polarization functions ( $\mathrm{d}$ functions on $\mathrm{Si}$ and $\mathrm{C}$, $\mathrm{p}$ functions on $\mathrm{H}$, or f functions on $\mathrm{Sm}$ ) has little or no beneficial effect on the quality of the results.
\end{abstract}




\section{Introduction}

In the late 1980s Power et al. reported two remarkable structures of homoleptic trialkyl complexes of lanthanum and samarium, $\mathrm{Ln}\left[\mathrm{CH}\left(\mathrm{SiMe}_{3}\right)_{2}\right]_{3}(\mathrm{Ln}=\mathrm{La}, \mathrm{Sm}) .{ }^{1}$ These compounds have a formal electron count of only 6 valence electrons if the $(4 \mathrm{f})^{\mathrm{n}}$ electrons are considered as core electrons. They adopt a highly distorted trigonal pyramidal structure, with C-Ln-C angles close to the tetrahedral value, and unusually short Ln•••Me contacts. Although the potential for the participation of agostic interactions (of the $\gamma-\mathrm{CH}$ type) was recognized, the molecular geometry was in fact rationalized on purely steric grounds, "the deviation from planarity occurring in order to maximize ligand-metal attractions and minimize ligand-ligand repulsions". ${ }^{1}$

The isolation an structural characterization of the tris(amido) samarium(III) derivative $\mathrm{Sm}\left[\mathrm{N}\left(\mathrm{SiMe}_{3}\right)_{2}\right]_{3},{ }^{2}$ has led us to examine and re-evaluate the structural features of the isolobal and isostructural tris(bis(trimethylsilyl)methyl) complexes. A further impetus to our work was also given by the recent crystallographic and DFT study ${ }^{3}$ on the related complex $\mathrm{Cp}^{*} \mathrm{La}\left\{\mathrm{CH}\left(\mathrm{SiMe}_{3}\right)_{2}\right\}_{2}$. Although this molecule is electronically more saturated relative to the title compounds, the presence of agostic interactions with the alkyl ligand $\beta$-Si-C bonds was unequivocally established. Close contacts between lanthanide centers and the $\mathrm{CH}\left(\mathrm{SiMe}_{3}\right)_{2}$ ligand have been observed in numerous instances. ${ }^{4,5}$ However, theoretical studies of these systems have remained rather limited, possibly because of the difficulty in handling the $f$ shell for lanthanide systems. Recently, however, Maron and Eisenstein have shown that the use of "large core" relativistic effective core potentials (RECPs) for the lanthanide atom, i.e., one which folds the $4 \mathrm{f}^{\mathrm{n}}$ shell into the core, greatly simplify the computational effort and yet provide sufficiently accurate results for lanthanide model systems. ${ }^{6-8}$ The above mentioned DFT study of the model $\mathrm{CpLa}\left\{\mathrm{CH}\left(\mathrm{SiMe}_{3}\right)_{2}\right\}_{2}$ system employed the ADF program in which the core electrons are present 
in the form of a relativistic frozen core potential. The calculations provided a very good match between the optimized and experimental structures, in particular the metric parameters related to the metal-ligand agostic interactions.

\section{Computational Details}

All calculations were carried out using the B3LYP functional and employing relativistic effective core potentials (RECP) on the La and Sm atoms. Unless specifically noted in the text, all calculations used the "large core" RECP in which the $5 \mathrm{~s}^{2} 5 \mathrm{p}^{6} 6 \mathrm{~s}^{2} 5 \mathrm{~d}^{1}$ electrons were explicitly treated as "valence" electrons with the remaining electrons replaced by the RECP. ${ }^{9,10}$ In the case

of Sm the RECP also replaces the electrons in the partially filled $4 \mathrm{f}^{5}$ shell which do not participate actively in the bonding. A contracted [5s $4 \mathrm{p} 3 \mathrm{~d}]$ valence basis set is employed for Sm. The starting basis set for the $\mathrm{CH}\left(\mathrm{SiMe}_{3}\right)_{2}$ ligands is the 6-31G basis. The effects of $\mathrm{d}$ functions on $\mathrm{C}$ and $\mathrm{Si}\left(6-31 \mathrm{G}^{*}\right)$, p functions on the hydrogen atoms, and polarization $\mathrm{f}$ functions on the Sm have also been explored.

For one set of calculations a "small core" RECP was used on Sm in which the $4 \mathrm{f}^{5}$ shell was explicitly treated as valence electrons. ${ }^{11}$ This ECP also includes the core-like $4 s^{2} 4 p^{6} 4 d^{10}$ shells of the same principal quantum number, along with the outer electrons already treated in the "large core" RECP. A contracted [5s 5p 4d 3f] Gaussian basis was used for Sm in this case. The geometry optimizations were performed without symmetry constraints $\left(\mathrm{C}_{1}\right.$ symmetry). The resultant structures correspond to stationary points with no net force on each nucleus, but second derivatives with respect to nuclear distortions were not computed. All calculations were carried out using Gaussian98. ${ }^{12}$ 
In the later discussion on van der Waals radii, standard radii ${ }^{13}$ were taken for $\mathrm{C}\left(\begin{array}{ll}1.70 & \AA\end{array}\right)$ and $\mathrm{Si}(2.10 \AA)$. For the lanthanides values were obtained from covalent radii in the alkyl complexes using the relation ${ }^{14} \mathrm{R}_{\mathrm{vdW}}=\mathrm{R}_{\mathrm{cov}}+0.80 \AA$, the $\mathrm{La}-\mathrm{C}(2.51 \AA)$ and $\mathrm{Sm}-\mathrm{C}(2.33 \AA)$ bond lengths in the structures of this paper, and $R_{\text {cov }}=0.77 \AA$ for carbon. This yields van der Waals radii of $2.54 \AA$ (La) and $2.36 \AA(\mathrm{Sm})$.

\section{Results and Discussion}

In discussing the results of the calculations it is useful to consider the experimental structure of the $\mathrm{Ln}\left[\mathrm{CH}\left(\mathrm{SiR}_{3}\right)_{2}\right]_{3}$ complexes as depicted in Scheme 1 where $\mathrm{Ln}=\mathrm{La}$ and $\mathrm{Sm}$. The structures exhibit the same features for each $\mathrm{CH}\left(\mathrm{SiMe}_{3}\right)_{2}$ ligand. The $\mathrm{SiMe}_{3}$ group which features the agostic Ln-Me interaction is located above the pyramid formed by the Ln-C bonds while the other $\mathrm{Si}^{\prime} \mathrm{Me}_{3}$ group is located below the pyramid with no close contacts with the metal center. Of the three methyl groups in the former $\mathrm{SiMe}_{3}$ moiety, one is in close proximity to the Sm while the other two methyl groups have no interactions with the metal.

Calculations were carried out, for both $\mathrm{La}$ and $\mathrm{Sm}$, on the $\mathrm{Ln}\left[\mathrm{CH}\left(\mathrm{SiR}_{2} \mathrm{Me}\right)\left(\mathrm{Si}^{\prime} \mathrm{R}_{3}\right)\right]_{3}$ systems where $\mathrm{R}=\mathrm{CH}_{3}$ (1), which represents the actual molecule, and $\mathrm{R}=\mathrm{H}$ (2), where all methyl groups except one closest to the Ln center are replaced with H. Finally the complex $\mathrm{Ln}\left[\mathrm{CH}\left(\mathrm{SiH}_{3}\right)\left(\mathrm{Si}^{\prime} \mathrm{H}_{3}\right)\right]_{3}(\mathbf{3})$ was calculated only for comparison purposes.

$<$ Scheme 1> 
The geometries were optimized with use of the B3LYP functional and various basis sets, the most thorough study being carried out for the Sm model system. The results pertaining to $\mathbf{1}$ and 2 are reported in Table 1 for $\mathrm{Sm}$ and in Table 2 for La. For each metal system, the relevant experimental parameters from the X-ray study are also reported in the corresponding table. The experimental crystallographic determinations are of sufficient quality to unambiguously establish the molecular geometry. The La structure has been determined more accurately and provides relatively reliable distance and angles to non-hydrogen atoms. The Sm structure, on the other hand, is of much lower quality (vide infra). The hydrogen atoms, however, were not located nor refined freely for either structure. The optimized geometries for the $\mathrm{R}=\mathrm{Me}$ and $\mathrm{H}$ systems with $\mathrm{R}=\mathrm{CH}_{3}$, shown in Figure 1 (a) and (b), are qualitatively the same for both metals while some important differences are observed for the simpler model compound $\mathbf{3}$ (with all $\mathrm{H}$ substituents), see Figure 1 (c). The geometric parameters for the latter model compounds are collected in Table 3.

<Table 1, Table 2 and Table 3; Figure 1>

\section{(a) Calculations on the full molecules $\operatorname{Ln}\left[\mathrm{CH}\left(\mathrm{SiMe}_{3}\right)_{2}\right]_{3}$}

The geometry of the full molecule $\mathbf{1}$ has been optimized only with the simplest basis set, which utilizes a large core Sm or La RECP (see Computational Details) and 6-31G bases for the $\mathrm{Si}, \mathrm{C}$ and $\mathrm{H}$ atoms. Although no polarization functions were used for any of the atoms, the calculated geometries reproduce quite well the experimental geometry. The most peculiar molecular feature is the pyramidal arrangement of the central $\mathrm{LnC}_{3}$ core. The computed C-Ln-C 
angles are identical to the experimental ones and are very close to the ideal value for a tetrahedral geometry. One $\mathrm{Si}(\mathrm{Me})_{2}-\mathrm{CH}_{3}$ arm of each alkyl ligand (facing the metal from the apex side of the $\mathrm{LnC}_{3}$ pyramid and containing the silicon atom labeled as Si in Figure 1), finds itself in relatively close proximity to the metal center, suggesting the existence of electronic (agostic) interactions. The other $\mathrm{Si}(\mathrm{Me})_{2}-\mathrm{CH}_{3}$ arm (with the silicon atom labeled as $\mathrm{Si}$ ' in Figure 1), on the other hand, is farther away from the metal. In spite of the sterically based rationalization given in the original report, ${ }^{1}$ we feel that the molecule should prefer a trigonal planar structure on the basis of purely steric arguments.

All bond distances are slightly longer than the experimental ones, as usually found at this level of theory, while all bond angles are reproduced to within $3^{\circ}$. A notable exception is the $\mathrm{CH}-\mathrm{Si}-\mathrm{CH}_{3}$ angle which is calculated $4.5^{\circ}$ greater than the experimental value for the $\mathrm{Sm}$ structure, while experimental and computed values for the same parameter are in much better agreement in the La structure. The poorer quality of the Sm structure leads us to believe that the experimental value of this parameter might have been determined with a lower precision than suggested by the reported esd's. In particular, we suspect that the position of the metal-bound C atom is erroneous for the Sm structure. In fact, other parameters related to this atom are also badly reproduced by the calculation, while the same parameters are correctly reproduced for the corresponding La structure. This is the case for the Ln-C distance and for the C-Si and C-Si' distances. It is particularly notable that the latter two distances are inexplicably quite different from each other (beyond the reported esd's) in the experimental Sm structure, while they are essentially identical in the La structure, as well as in all our computational results (including those on the simpler model compound at all levels of theory, vide infra). 
The presence of agostic interactions between the $\mathrm{Ln}$ center and the $\mathrm{Si}\left(\mathrm{CH}_{3}\right)_{2}-\mathrm{CH}_{3}$ arm is strongly suggested by several parameters. The most notable ones are the Ln-C-Si angles. These are much smaller $\left(<\mathrm{La}-\mathrm{C}-\mathrm{Si}=104^{\circ}(\right.$ calcd $), 102^{\circ}($ exptl $\left.)\right)$ than the $\mathrm{Ln}-\mathrm{C}-\mathrm{Si}{ }^{\prime}$ angles $\left(<\mathrm{La}-\mathrm{C}-\mathrm{Si}^{\prime}=\right.$ $121^{\circ}$ (calcd), $121^{\circ}$ (exptl)) and smaller than the ideal tetrahedral value. The Ln-C-Si' angles are comparatively larger than the tetrahedral value. A second parameter is the $\mathrm{Si}_{-} \mathrm{CH}_{3}(\cdots \mathrm{Ln})$ distance (namely, the distance to the methyl group which is closest to the lanthanide metal center). This distance is significantly longer $(0.033-0.035 \AA$ calc., $0.05-0.09 \AA$ exptl.) than all other $\mathrm{Si}-\mathrm{CH}_{3}$ distances. These two features are clear indications of an electronic interaction between the metal center and the $\beta-\mathrm{SiC}$ (i.e., the $\mathrm{Si}_{\beta}-\mathrm{C}_{\gamma}$ ) bond. It is notable that the angular distortion is strongest at the $\mathrm{C}_{\alpha}$ atom and weakest at the $\mathrm{Si} \beta$ atom, as might be expected for an $\alpha$ agostic interaction. On the other hand, the bond distance trends analyzed above clearly indicate that the $\mathrm{Sm}$ atom interacts with the $\beta$-SiC bond (which is lengthened) and not with the $\alpha$-CSi bond. Additional indications for the presence of $\beta$-SiC agostic interactions are the relatively short $\mathrm{Ln} \cdots \mathrm{Si}$ and $\mathrm{Ln} \cdots \mathrm{C}$ contacts that are significantly shorter than the sums of the van der Waals radii. For example, using an estimated radius of $2.5 \AA$ for La (see Computational Details), the sums of van der Waals radii for $\mathrm{La} \cdots \mathrm{Si}(4.6 \AA)$ and $\mathrm{La} \cdots \mathrm{C}(4.2 \AA)$ interactions are significantly

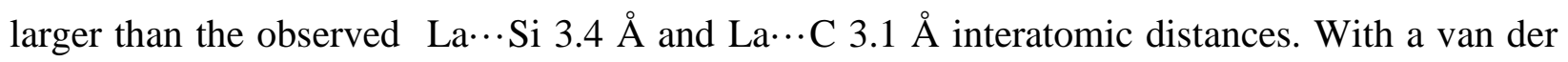
Waals radius of $2.33 \AA$ for $\mathrm{Sm}$, the same analysis shows the observed $\mathrm{Sm} \cdots \mathrm{Si}$ and $\mathrm{Sm} \cdots \mathrm{C}$ contacts of 3.3 and $3.0 \AA$ would also be less than the sums of van der Waals radii.

Because of the close distance, the presence of $\mathrm{Ln} \cdots \mathrm{H}$ interactions may also be questioned, (see Scheme 1). Although the accurate position of the $\mathrm{H}$ atoms is not available from the X-ray studies, the computational results help the analysis of this interaction. Two indicators are strongly suggesting that the $\mathrm{Ln} \cdots(\mathrm{H}-\mathrm{C})$ interaction is rather repulsive in nature. The first one 
is the nearly staggered orientation, with respect to the $\mathrm{Ln} \cdots \mathrm{Si}$ axis, adopted by the $\mathrm{CH}_{3}$ fragments closest to the metal center. The dihedral $\mathrm{Ln} \cdots \mathrm{Si}-\mathrm{C}-\mathrm{H}$ angles are in the proximity of $\pm 60^{\circ}$ for all calculations on both metal systems (see Table 1 and Table 2), while an attractive interaction would be expected to place a single $\mathrm{H}$ atom as close as possible to the metal center, with a dihedral angle close to zero. The Ln-C-Si-C dihedral angle, on the other hand, is close to zero, in agreement with the presence of the $\beta$-Si-C interaction. The second indicator is the tilting of the Me group away from the metal, as shown by the greater than tetrahedral value for the Si$\mathrm{C}-\mathrm{H}$ angles relating to the two closest $\mathrm{H}$ atoms, and smaller value for the third angle. An analogous situation is evident from the DFT results for the compound $\left(\mathrm{C}_{5} \mathrm{H}_{5}\right) \mathrm{La}\left[\mathrm{CH}\left(\mathrm{SiMe}_{3}\right)_{2}\right]_{2} .^{3}$ It is interesting to observe that the $\mathrm{C}-\mathrm{H}$ distances for the two $\mathrm{C}-\mathrm{H}$ bonds closest to the $\mathrm{Ln}$ center are marginally longer than the third $\mathrm{C}-\mathrm{H}$ bond. While the difference is quite small, this phenomenon is consistently found for all Me groups within the same molecule and also for the model system at all levels of theory (vide infra). This trend is consistent with the carbon rehybridization caused by the distortion. In fact, the $\mathrm{C}-\mathrm{H}$ bonds with a greater $\mathrm{Si}-\mathrm{C}-\mathrm{H}$ angle have a greater $\mathrm{C} p$ character, leading to bond lengthening, while those with a smaller Si-C-H angle have a greater $\mathrm{C} s$ character, leading to bond shortening. Therefore, there are no indications whatsoever for the presence of $\gamma-\mathrm{C}-\mathrm{H}$ agostic interactions in these molecules, while the metal center establishes $\beta$-Si-C interactions with all three alkyl ligands. Once again, an analogous situation exists for compound $\left(\mathrm{C}_{5} \mathrm{H}_{5}\right) \mathrm{La}\left[\mathrm{CH}\left(\mathrm{SiMe}_{3}\right)_{2}\right]_{2}{ }^{3}$

\section{(b) Calculations on the $\mathrm{Ln}\left[\mathrm{CH}\left(\mathrm{SiH}_{2} \mathrm{Me}\right)\left(\mathrm{Si}^{\prime} \mathrm{H}_{3}\right)\right]_{3}$ model system.}

The data in Table 1 and Table 2 and a comparison of parts (a) and (b) of Figure 1 illustrate the validity of the chosen model to represent the essential metal-ligand interactions. All optimized parameters obtained at the 6-31G level are close to those obtained for the real 
molecule at the same level of theory. The largest differences can be attributed to the steric effect of the bulkier $\mathrm{SiMe}_{3}$ groups in the real molecule, as clearly illustrated by the much smaller Ln-CSi' and Si-C-Si' angles in the model compound.

The effect of an increase in the quality of the basis set was explored for the model system and only for the Sm system. As shown in Table 1, additional calculations were carried out by adding polarization functions on the $\mathrm{CH}_{3}$ hydrogen atoms $(p)$, on all silicon atoms $(d)$, on the $\mathrm{C}$ atoms ( $d$, plus the two above polarization functions on $\mathrm{H}$ and $\mathrm{Si})$, and on the $\mathrm{Sm}$ atom $(f)$. The energetic gain and the structural modifications are substantial only when $d$ functions are introduced on the $\mathrm{Si}$ and $\mathrm{C}$ atoms, see Table 1, while they are very minor when $p$ functions are added to the $\mathrm{H}$ atoms and especially when $f$ functions are added to the Sm atom. The added polarization functions do not qualitatively affect the nature of the agostic interactions, although the $\mathrm{Sm} \cdots \mathrm{Si}$ and $\mathrm{Sm} \cdots \mathrm{C}$ contacts do get marginally shorter, especially upon adding $d$ functions on the $\mathrm{Si}$ atoms. The C-Si distances also shorten significantly upon addition of the Si $d$ function. No significant changes for the Sm-ligand interactions ( $\sigma$ bonding and agostic) result from the addition of the $f$ functions, thus these interactions can adequately be described by using only the metal $s, p$ and $d$ orbitals.

A final calculation was also carried out with the "small core" RECP and basis for the Sm atom in which the unpaired electrons in the $4 \mathrm{f}^{5}$ shell were explicitly treated along with all other electrons outside the $[\mathrm{Ar}] 3 \mathrm{~d}^{10}$ core (see Computational Details), but without polarization functions on the $\mathrm{H}, \mathrm{C}$ and $\mathrm{Si}$ atoms. With respect to the large core calculation without polarization functions, the major noticeable difference is a slight shortening of all bond distances related to the $\mathrm{Sm}$ atom, whereas all other distances display more marginal changes. This result is analogous to that obtained by Maron and Eisenstein on the simple $\mathrm{Ln}\left(\mathrm{NH}_{2}\right)_{3}$ model systems. ${ }^{6}$ 
Finally we note that a second local minimum for the structure is also obtained for the model complex using the large core RECP. Starting from a different initial geometry, the molecule optimized to a new conformer (Figure 2) that is characterized by agostic interactions with only two of the alkyl substituents, while the third one adopts a staggered orientation of the $\mathrm{SiH}_{2} \mathrm{Me}$ group relative to the $\mathrm{Sm}-\mathrm{C}$ bond. The loss of one agostic interaction with a $\mathrm{Si}-\mathrm{C}$ bond is compensated by the strengthening of the other two $\mathrm{Sm} \cdots(\mathrm{Si}-\mathrm{C})$ interactions. In fact, the two

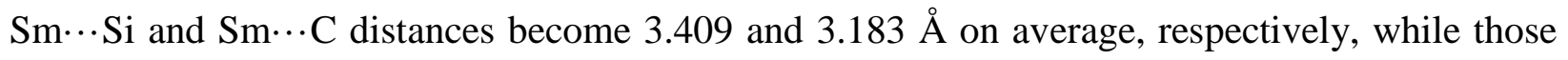
to the non-interacting alkyl group are lengthened to 3.57 and $4.03 \AA$. The total energy of this optimized geometry is slightly higher $(0.4 \mathrm{kcal} / \mathrm{mol})$ relative to the triply agostic conformer in the 6-31G basis with p polarization functions on $\mathrm{H}$. This small difference suggests a facile pathway for the exchange of the interacting $\mathrm{Si}-\mathrm{C}$ bonds in the parent compound by rotation about the $\mathrm{C}-\mathrm{Si}$ bond and is consistent with the observation of single resonances in the ${ }^{1} \mathrm{H}$ and ${ }^{13} \mathrm{C}$ NMR spectra of compound $\mathrm{La}\left[\mathrm{CH}\left(\mathrm{SiMe}_{3}\right)_{2}\right]_{3}$ for all $\mathrm{SiMe}_{3}$ groups. ${ }^{1}$ Obviously, a second process involving the inversion of the $\mathrm{LaC}_{3}$ pyramid or rotation about the $\mathrm{Sm}-\mathrm{C}$ bond must also be invoked to account for the experimental result.

$<$ Figure 2>

\section{(c) Calculations on the $\operatorname{Ln}\left[\mathrm{CH}\left(\mathrm{SiH}_{3}\right)_{2}\right]_{3}$ model system.}

As shown in Figure 1 (c) and Table 3, the replacement of the residual $\mathrm{CH}_{3}$ groups with $\mathrm{H}$ atoms in the model system discussed in the previous section maintains the pyramidal structure of the central $\mathrm{LnC}_{3}$ core. The degree of pyramidalization is quite comparable with those of the two systems discussed above and with those of the experimental structures. This new modification, 
however, has the more profound effect of replacing the agostic $\beta$-Si-C interaction with a $\beta-\mathrm{Si}-\mathrm{H}$ interaction. In this respect, the present model is no longer chemically meaningful.

The $\beta$-Si-H agostic interactions in this simpler model are stronger than their $\beta$-Si-C counterparts discussed above. This is clearly indicated by the shorter Ln $\cdots$ Si contacts (by over $0.2 \AA$ ) and by the smaller Ln-C-Si angles (by $\left.10^{\circ}\right)$. Additional indications of the presence of strong agostic interactions are the close $\mathrm{Ln} \cdots \mathrm{H}$ contacts and the significant lengthening of the interacting $\mathrm{Si}-\mathrm{H}$ bond relative to the other non-interacting bonds (see Table 3).

\section{(d) Discussion of the electronic structure.}

In the preceding sections the discussion has focused on the structural results of the calculations. In this section some aspects of the electronic structure of the complexes will be discussed briefly with particular attention to $\mathrm{Sm}\left[\mathrm{CH}\left(\mathrm{SiMeR}_{2}\right)\left(\mathrm{SiR}_{3}\right)\right]_{3}$ molecules where $\mathrm{R}=\mathrm{Me}$

and $\mathrm{H}$. For a neutral $\mathrm{Sm}$ atom the ground state has the atomic configuration $\ldots\left[4 \mathrm{f}^{5}\right] 5 \mathrm{~s}^{2} 5 \mathrm{p}^{6} 6 \mathrm{~s}^{2}$ $5 d^{1}$. In the present calculations the electrons in the partially occupied $4 \mathrm{f}$ shell denoted by brackets are replaced by the RECP, and the filled outer core 5s and 5p electrons are explicitly treated in the calculations. These shells will be omitted in the following discussion. From a standard Mulliken population analysis of the molecular DFT wavefunction in $\mathrm{Sm}\left[\mathrm{CH}\left(\mathrm{SiMeR}_{2}\right)\left(\mathrm{SiR}_{3}\right)\right]_{3}$ using the 6-31G basis, one obtains the following atomic populations for Sm:

$$
\begin{array}{ll}
R=M e & 6 s^{0.42} 6 p^{0.53} 5 d^{1.50} \\
R=H & 6 s^{0.41} 6 p^{0.31} 5 d^{1.32}
\end{array}
$$

leading to overall atomic charges of $+0.54(\mathrm{R}=\mathrm{Me})$ and $+0.84(\mathrm{R}=\mathrm{H})$ for $\mathrm{Sm}$ and hence overall charges of -0.18 and -0.28 on each of the three alkyl ligands, respectively. In addition to 
observing that this analysis portrays the $\mathrm{Sm}$ as much less ionic than the formal $\mathrm{Sm}(\mathrm{III})$ valence state would indicate, the other notable feature is the significant amount of $5 \mathrm{~d}$ admixture in the molecular orbitals. Analogous results are obtained for La complexes where a slight (0.1 electron) increase in d population is obtained.

$<$ Figure 3>

This 5d participation in the bonding is particularly evident in the highest occupied molecular orbitals. In the B3LYP calculations the highest 3 occupied orbitals represent the Sm$\mathrm{C}$ bonding orbitals. The lower, more strongly bound orbitals are describing the $\mathrm{Si}-\mathrm{C}-\mathrm{H}$ bonds in the ligands. The set of 3 highest occupied orbitals is comprised of a degenerate set of MOs $(e$ symmetry) and another MO ( $a$ symmetry) at slightly lower energy. Contour plots of these orbitals are shown in Figure 3 for the case $\mathrm{Sm}\left[\mathrm{CH}(\mathrm{SiMeH})\left(\mathrm{SiH}_{3}\right)\right]_{3}$. For the $e$ set a decomposition of the electron density in each MO gives 17 percent $\mathrm{Sm}(5 \mathrm{~d})$ character and $83 \%$ ligand character. For the $a$ orbital the relative populations are $10 \% \mathrm{Sm}(6 \mathrm{~s})$ and $88 \%$ ligand character. The two highest orbitals provide $0.68 \mathrm{e}^{-}$of the total $1.32 \mathrm{e}^{-}$of $5 \mathrm{~d}$ population on $\mathrm{Sm}$. In the figure the $e$ MOs, which are predominantly s-p hybrid orbitals on the alpha carbon atoms, interact with the $5 \mathrm{~d}$ orbitals on $\mathrm{Sm}$. For the $a \mathrm{MO}$ the symmetric combination of similar orbitals on the alkyl ligands interacts with the 6 s orbital on $\mathrm{Sm}$, where the nodal structure in the region of the $5 \mathrm{~s}$ is also evident.

The lanthanide trihalides ${ }^{15}$ present a somewhat analogous situation to the tris-alkyl complexes in that there is a very soft mode corresponding to motion between planar and pyramidal structures. The results from calculations ${ }^{16-19}$ show that many of the $\mathrm{LnF}_{3}$ molecules 
are pyramidal. The calculations also show a greater tendency for heavier trihalides to be planar, but there is not unanimity in the predictions. For example, DFT calculations ${ }^{19}$ on $\mathrm{LnCl}_{3}$ molecules give pyramidal structures (but with larger bond angles than trifluorides), while other SCF and MP2 calculations show trichlorides to be planar. Analysis of the orbitals from the DFT calculations on $\mathrm{LnX}_{3}$ species for $\mathrm{X}=\mathrm{F}, \mathrm{Cl}, \mathrm{Br}$ and I showed as much as 15-20 percent d orbital character for the cases $\mathrm{X}=\mathrm{Cl}$ and $\mathrm{I}$. From the experimental and theoretical studies one could conclude that the most ionic $\mathrm{LnF}_{3}$ molecules show the greatest tendency for nonplanar structures. Additional information regarding possible agostic interactions can be obtained from bond overlaps from the Mulliken population analysis. In the real molecule $(\mathrm{R}=\mathrm{Me})$ the $\mathrm{Sm}-\mathrm{C}$ bond overlap is 0.075 for the agostic methyl groups compared to 0.238 for the $\mathrm{Sm}-\mathrm{C}_{\alpha}$ bonds and 0.01 0.02 for all other $\mathrm{Sm}-\mathrm{C}$ interactions. The $\mathrm{Sm}-\mathrm{H}$ bond overlaps for the two closest $\mathrm{H}$ atoms in each agostic methyl group are 0.026 and 0.011 , several times the magnitude of other Sm-H interactions.

After submission of this manuscript, we have learned about an independent study by Perrin, Maron, Eisenstein and Lappert ${ }^{20}$ on the same system. This study describes the bonding, including to the $\beta$-Si-C bond, as essentially purely electrostatic on the basis of a natural bond orbital (NBO) analysis. ${ }^{21}$ The same study, however, highlights the importance of the lanthanide $d$ orbitals in enforcing the pyramidal configuration at the metal center through a $2^{\text {nd }}$ order JahnTeller effect.

\section{Conclusions}

The present study has shown that the unusual structural features of compounds $\mathrm{Ln}\left[\mathrm{CH}\left(\mathrm{SiMe}_{3}\right)_{2}\right]_{3}$ are associated with $\beta-\mathrm{Si}-\mathrm{C}$ agostic interactions established by the metal center 
with all three alkyl ligands rather than $\gamma-\mathrm{C}-\mathrm{H}$ agostic interactions. The interaction between the lanthanide metal and the $\gamma-\mathrm{C}-\mathrm{H}$ bonds are in fact repulsive. The essential features of these structures can therefore be correctly reproduced by using the $\mathrm{Ln}\left[\mathrm{CH}\left(\mathrm{SiH}_{2} \mathrm{Me}\right)\left(\mathrm{Si}^{\prime} \mathrm{H}_{3}\right)\right]_{3}$ model system. The replacement of the last Me group in each alkyl ligand with a $\mathrm{H}$ atom, while maintaining the basic experimental geometry with a triple $\beta$-agostic interaction, no longer provides a faithful chemical representation of the real molecule. The use of several ameliorated basis sets with the addition of polarization functions on the $\mathrm{H}, \mathrm{C}, \mathrm{Si}$ and $\mathrm{Sm}$ atoms does not allow a significantly better description of the molecular features. Finally, the excellent match of the optimized data with the experimentally better determined La structure and the poorer match with the lower quality Sm structure shows an example of the utility of computational chemistry for the assessment of experimental data.

Acknowledgements. We acknowledge support from Laboratory Directed Research and Development at Los Alamos. Los Alamos National Laboratory is operated by the University of California for the U.S. Department of Energy under Contract W-7405-ENG-36. R.P. is grateful to CINES (Montpellier, France) for granting free computer time and the G. T. Seaborg Institute for Transactinium Science for sponsoring a stay at Los Alamos National Laboratory. We thank Odile Eisenstein for sending us a preprint of her parallel study. ${ }^{20}$ 


\section{References}

(1) Hitchcock, P. B.; Lappert, M. F.; Smith, R. G.; Bartlett, R. A.; Power, P. P. J. Chem. Soc. Chem. Comm. 1988, 1007.

(2) Brady, E. D.; Clark, D. L.; Gordon, J. C.; Hanusa, T. P.; Hay, P. J.; Keogh, D. W.; Poli, R.; Scott, B. L. in preparation.

(3) Klooster, W. T.; Brammer, L.; Schaverien, C. J.; Budzelaar, P. H. M. J. Am. Chem. Soc. 1999, 121, 1381.

(4) Heeres, H. J.; Meetsma, A.; Teuben, J. H.; Rogers, R. D. Organometallics 1989, $107,8103$.

(5) Giardello, M. A.; Conticello, V. P.; Brard, L.; Sabat, M.; Rheingold, A. L.; Stern, C. L.; Marks, T. J. J. Am. Chem. Soc. 1994, 116, 10212.

(6) Maron, L.; Eisenstein, O. J. Phys. Chem. A 2000, 104, 7140.

(7) Maron, L.; Eisenstein, O. New J. Chem. 2001, 25, 255.

(8) Eisenstein, O.; Maron, L. J. Organomet. Chem. 2002, 647, 190.

(9) Dolg, M.; Stoll, H.; Savin, A.; Preuss, H. Theo. Chem. Acta 1989, 75, 173.

(10) Dolg, M.; Stoll, H.; Preuss, H. Theo. Chem. Acta 1989, 85, 441.

(11) Dolg, M.; Stoll, H.; Preuss, H. J. Chem. Phys. 1989, 90, 1730.

(12) Frisch, M. J.; Trucks, G. W.; Schlegel, H. B.; Scuseria, G. E.; Robb, M. A.; Cheeseman, J. R.; Zakrzewski, V. G.; Montgomery, J. A.; Stratmann, R. E.; Burant, J. C.; Dapprich, S.; Millam, J. M.; Daniels, A. D.; Kudin, K. N.; Strain, M. C.; Farkas, O.; Tomasi, J.; Barone, V.; Cossi, M.; Cammi, R.; Mennucci, B.; Pomelli, C.; Adamo, C.; Clifford, S.; Ochterski, J.; Petersson, G. A.; Ayala, P. Y.; Cui, Q.; Morokuma, K.; Malick, D. K.; Rabuck, A. 
D.; Raghavachari, K.; Foresman, J. B.; Cioslowski, J.; Ortiz, J. V.; Stefanov, B. B.; Liu, G.; Liashenko, A.; Piskorz, P.; Komaromi, I.; Gomperts, R.; Martin, R. L.; Fox, D. J.; Keith, T.; AlLaham, M. A.; Peng, C. Y.; Nanayakkara, A.; Gonzalez, C.; Challacombe, M.; Gill, P. M. W.;

Johnson, B. G.; Chen, W.; Wong, M. W.; Andres, J. L.; Head-Gordon, M.; Replogle, E. S.; Pople, J. A. Gaussian 98; Revision A.9 ed.; Gaussian, Inc.: Pittsburgh PA, 1998.

(13) Bondi, A. J. Phys. Chem. 1954, 68, 441.

(14) Pyykko, P. Chem. Rev. 1997, 97, 597.

(15) Hargittai, M. Chem. Rev. 2000, 100, 2233.

(16) Cundari, T. R.; Sommerer, S. O.; Strohecker, L. A.; Tippett, L. J. Chem. Phys. 1996, 103,7058 .

(17) Joubert, L.; Picard, G.; Legendre, J.-J. Inorg. Chem. 1998, 37, 1984.

(18) Lanza, G.; Fragala, I. L. Chem. Phys. Lett. 1996, 255, 341.

(19) Adamo, C.; Maldivi, P. J. Phys. Chem. 1998, 102, 6812.

(20) Perrin, L.; Maron, L.; Eisenstein, O.; Lappert, M. F. submitted.

(21) Reed, A. E.; Curtiss, L. A.; Weinhold, F. Chem. Rev. 1988, 88, 899. 
Table 1. Comparison of optimized and experimental structural parameters for $\mathrm{Sm}\left[\mathrm{CH}\left(\mathrm{SiR}_{2} \mathrm{Me}\right)\left(\mathrm{Si}^{\prime} \mathrm{R}_{3}\right)\right]_{3}{ }^{\mathrm{a}}$

\begin{tabular}{|c|c|c|c|c|c|c|c|c|}
\hline & \multicolumn{2}{|c|}{$\mathrm{R}=\mathrm{Me}$} & \multicolumn{6}{|c|}{$\mathrm{R}=\mathrm{H}$} \\
\hline & $6-31 \mathrm{G}$ & $\exp$ & $6-31 \mathrm{G}$ & $\begin{array}{l}6-31 \mathrm{G} \\
\left(\mathrm{H}^{* *}\right) \\
\end{array}$ & $\begin{array}{c}6-31 \mathrm{G} \\
\left(\mathrm{Si}^{*}\right) \\
\end{array}$ & $\begin{array}{c}6-31 \mathrm{G} \\
\left(\mathrm{H}^{* *} \mathrm{C} * \mathrm{Si}^{*}\right) \\
\end{array}$ & $\begin{array}{c}6-31 G \\
\operatorname{Sm}\left(f_{\text {pol }}\right) \\
\end{array}$ & $\begin{array}{r}6-31 G \\
\text { Sm SC } \\
\end{array}$ \\
\hline $\mathrm{Sm}-\mathrm{C}$ & 2.459 & $2.33(2)$ & 2.449 & 2.450 & 2.457 & 2.460 & 2.439 & 2.420 \\
\hline $\mathrm{Sm} \cdots \mathrm{Si}$ & 3.49 & $3.326(7)$ & 3.46 & 3.45 & 3.43 & 3.43 & 3.45 & 3.40 \\
\hline $\mathrm{Sm} \cdots \mathrm{C}$ & 3.24 & $3.04(2)$ & 3.32 & 3.29 & 3.28 & 3.27 & 3.31 & 3.24 \\
\hline \multirow[t]{2}{*}{$\mathrm{Sm} \cdots \mathrm{H}$} & 2.96 & - & 3.01 & 2.99 & 2.95 & 2.92 & 3.02 & 2.95 \\
\hline & 3.15 & - & 3.20 & 3.23 & 3.29 & 3.25 & 3.24 & 3.18 \\
\hline $\mathrm{C}-\mathrm{Si}$ & 1.906 & $1.80(3)$ & 1.900 & 1.898 & 1.861 & 1.860 & 1.899 & 1.896 \\
\hline C-Si' & 1.906 & $1.94(3)$ & 1.900 & 1.899 & 1.864 & 1.864 & 1.899 & 1.894 \\
\hline $\mathrm{Si}-\mathrm{CH}_{3}(\cdots \mathrm{Sm})$ & 1.956 & $1.95(3)$ & 1.950 & 1.954 & 1.921 & 1.923 & 1.951 & 1.951 \\
\hline $\mathrm{Si}-\mathrm{CH}_{3}$ (other) & 1.923 & $1.86(5)$ & - & - & - & - & - & - \\
\hline \multirow[t]{2}{*}{$\mathrm{C}-\mathrm{H}(\cdots \mathrm{Sm})$} & 1.103 & - & 1.103 & 1.100 & 1.105 & 1.103 & 1.102 & 1.102 \\
\hline & 1.099 & - & 1.099 & 1.097 & 1.100 & 1.098 & 1.099 & 1.099 \\
\hline C-H(other) & 1.097 & - & 1.096 & 1.094 & 1.097 & 1.096 & 1.096 & 1.096 \\
\hline C-Sm-C & 110.2 & $110.3(10)$ & 108.4 & 108.4 & 108.2 & 108.4 & 108.7 & 107.6 \\
\hline $\mathrm{Sm}-\mathrm{C}-\mathrm{Si}$ & 103.9 & $106.6(12)$ & 104.6 & 104.4 & 104.2 & 104.4 & 104.6 & 103.3 \\
\hline Sm-C-Si' & 123.0 & $124.0(13)$ & 117.0 & 117.0 & 116.7 & 116.7 & 117.1 & 119.3 \\
\hline Si-C-Si' & 117.4 & $117.9(13)$ & 114.9 & 115.2 & 114.9 & 115.3 & 115.1 & 115.8 \\
\hline $\mathrm{CH}-\mathrm{Si}-\mathrm{CH}_{3}$ & 109.7 & $105.2(12)$ & 111.1 & 111.0 & 111.5 & 111.0 & 111.1 & 110.8 \\
\hline \multirow[t]{2}{*}{$\mathrm{CH}-\mathrm{Si}-\mathrm{R}$} & 114.3 & $114.8(16)$ & 111.3 & 111.6 & 111.0 & 111.2 & 111.4 & 111.0 \\
\hline & 114.3 & $116.9(13)$ & 115.0 & 114.9 & 114.9 & 115.0 & 114.9 & 115.2 \\
\hline \multirow[t]{2}{*}{$\mathrm{Si}-\mathrm{C}-\mathrm{H}(\cdots \mathrm{Sm})$} & 114.1 & - & 113.6 & 113.6 & 114.0 & 114.0 & 113.7 & 113.6 \\
\hline & 113.0 & - & 112.3 & 112.4 & 112.7 & 112.7 & 112.4 & 112.5 \\
\hline Si-C-H(other) & 108.0 & - & 108.6 & 108.7 & 108.7 & 109.6 & 108.5 & 108.4 \\
\hline Sm-C-Si-C & 14.0 & $14.4(17)$ & 15.2 & 13.9 & 18.1 & 17.1 & 15.4 & 15.6 \\
\hline \multirow[t]{2}{*}{$\mathrm{Sm} \cdots \mathrm{Si}-\mathrm{C}-\mathrm{H}$} & -57.3 & - & -54.8 & -55.2 & -51.9 & -52.0 & -55.7 & -55.1 \\
\hline & 68.8 & - & 70.7 & 70.2 & 73.5 & 73.0 & 69.8 & 70.4 \\
\hline $\begin{array}{l}\text { Rel. energy } \\
\text { (hartrees) }\end{array}$ & & & 0 & -0.01962 & -0.21630 & -0.24904 & -0.00451 & \\
\hline
\end{tabular}

${ }^{a}$ Values are given as averages of geometrically equivalent structural parameters. 
Table 2. Comparison of optimized and experimental structural parameters for $\mathrm{La}\left[\mathrm{CH}\left(\mathrm{SiR}_{2} \mathrm{Me}\right)\left(\mathrm{Si}^{\prime} \mathrm{R}_{3}\right)\right]_{3}$. $^{\mathrm{a}}$

\begin{tabular}{|c|c|c|c|}
\hline & \multicolumn{2}{|c|}{$\mathrm{R}=\mathrm{Me}$} & \multirow{3}{*}{$\begin{array}{c}\mathrm{R}=\mathrm{H} \\
6-31 \mathrm{G} \\
\left(\mathrm{H} * * \mathrm{C} * \mathrm{Si}^{*}\right)\end{array}$} \\
\hline & $6-31 \mathrm{G}$ & $\exp$ & \\
\hline & & & \\
\hline $\mathrm{La}-\mathrm{C}$ & 2.554 & $2.516(10)$ & 2.552 \\
\hline $\mathrm{La} \cdots \mathrm{Si}$ & 3.54 & $3.411(3)$ & 3.52 \\
\hline $\mathrm{La} \cdots \mathrm{C}$ & 3.31 & 3.12 & 3.34 \\
\hline \multirow[t]{2}{*}{$\mathrm{La} \cdots \mathrm{H}$} & 3.02 & - & 3.01 \\
\hline & 3.20 & - & 3.29 \\
\hline $\mathrm{C}-\mathrm{Si}$ & 1.903 & $1.841(10)$ & 1.860 \\
\hline C-Si' & 1.903 & $1.837(11)$ & 1.861 \\
\hline $\mathrm{Si}-\mathrm{CH}_{3}(\cdots \mathrm{La})$ & 1.958 & $1.923(10)$ & 1.925 \\
\hline $\mathrm{Si}-\mathrm{CH}_{3}$ (other) & 1.923 & $1.875(15)$ & - \\
\hline \multirow[t]{2}{*}{ C-H( $\cdots$ La $)$} & 1.103 & - & 1.102 \\
\hline & 1.099 & - & 1.099 \\
\hline C-H(other) & 1.097 & - & 1.095 \\
\hline C-La-C & 111.5 & $109.9(4)$ & 108.9 \\
\hline $\mathrm{La}-\mathrm{C}-\mathrm{Si}$ & 104.1 & $101.9(4)$ & 105.0 \\
\hline La-C-Si' & 120.6 & $121.0(6)$ & 116.6 \\
\hline Si-C-Si' & 118.3 & $121.6(6)$ & 114.8 \\
\hline $\mathrm{CH}-\mathrm{Si}-\mathrm{CH}_{3}$ & 110.3 & $109.7(4)$ & 111.8 \\
\hline \multirow[t]{2}{*}{$\mathrm{CH}-\mathrm{Si}-\mathrm{R}$} & 113.6 & $113.4(6)$ & 111.5 \\
\hline & 114.7 & $115.2(5)$ & 114.6 \\
\hline \multirow[t]{2}{*}{$\mathrm{Si}-\mathrm{C}-\mathrm{H}(\cdots \mathrm{La})$} & 114.2 & - & 114.1 \\
\hline & 113.0 & - & 112.6 \\
\hline Si-C-H(other) & 107.8 & - & 109.1 \\
\hline La-C-Si-C & 13.4 & $13.9(7)$ & 13.6 \\
\hline \multirow[t]{2}{*}{$\mathrm{La} \cdots \mathrm{Si}-\mathrm{C}-\mathrm{H}$} & 57.0 & - & 53.9 \\
\hline & -68.9 & - & -71.3 \\
\hline
\end{tabular}

${ }^{a}$ Values are given as averages of geometrically equivalent structural parameters. 
Table 3. Comparison of optimized structural parameters for $\mathrm{Ln}\left[\mathrm{CH}\left(\mathrm{SiH}_{3}\right)_{2}\right]_{3}(\mathrm{Ln}=\mathrm{La}, \mathrm{Sm}) .{ }^{\mathrm{a}}$

\begin{tabular}{l|c|c} 
& Ln $=\mathrm{La}$ & $\mathrm{Ln}=\mathrm{Sm}$ \\
\hline $\mathrm{Ln}-\mathrm{C}$ & 2.591 & 2.480 \\
$\mathrm{Ln} \cdots \mathrm{Si}$ & 3.280 & 3.214 \\
$\mathrm{Ln} \cdots \mathrm{H}$ & 2.646 & 2.592 \\
$\mathrm{C}-\mathrm{Si}$ & 1.840 & 1.881 \\
$\mathrm{C}-\mathrm{Si}$ & 1.858 & 1.895 \\
$\mathrm{Si}-\mathrm{H}(\cdots$ La) & 1.548 & 1.567 \\
$\mathrm{Si}-\mathrm{H}($ other $)$ & 1.487 & 1.500 \\
$\mathrm{C}-\mathrm{Ln}-\mathrm{C}$ & 113.05 & 112.01 \\
Ln-C-Si & 93.94 & 93.92 \\
Ln-C-Si & 116.60 & 116.90 \\
Si-C-Si' & 118.25 & 117.94 \\
CH-Si-H( $\cdots$ La) & 104.75 & 103.31 \\
CH-Si-H(other) & 116.59 & 117.11 \\
& 117.41 & 117.51 \\
La-C-Si- H & 0.6 & 0.3
\end{tabular}

${ }^{\text {a }}$ Values are given as averages of geometrically equivalent structural parameters. 


\section{Captions for Figures}

Figure 1. Views of the optimized geometries for compounds $\operatorname{Ln}\left[\mathrm{CH}\left(\mathrm{SiR}_{2} \mathrm{R}^{\prime}\right)\left(\mathrm{Si}^{\prime} \mathrm{R}_{3}\right)\right]_{3}(\mathrm{Ln}=$ La, Sm). (a): R= R' = Me; (b) $R=H, R^{\prime}=\mathrm{Me}(\mathrm{c}) \mathrm{R}=\mathrm{R}^{\prime}=\mathrm{H}$. The Si' center denotes the ligand without agostic methyl interactions with the metal.

Figure 2. A top view of the $\mathrm{Sm}\left[\mathrm{CH}\left(\mathrm{SiH}_{2} \mathrm{CH}_{3}\right)\left(\mathrm{Si}^{\prime} \mathrm{H}_{3}\right)\right]_{3}$ conformer with only two Sm-alkyl agostic interactions.

Figure 3. Contour plots of the three highest occupied orbitals of $\mathrm{Sm}\left[\mathrm{CH}\left(\mathrm{SiH}_{2} \mathrm{CH}_{3}\right)\left(\mathrm{SiH}_{3}\right)\right]_{3}$ from top view of molecule: MOs 79 and 78 (e symmetry), MO 77( a symmetry). 
Figure 1

(a)

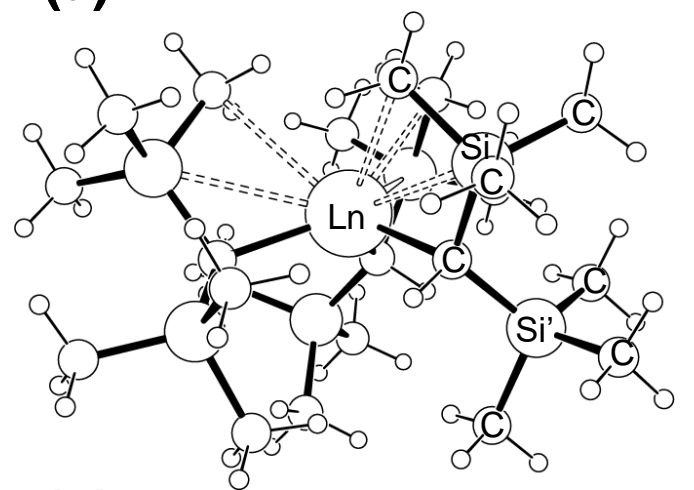

(b)

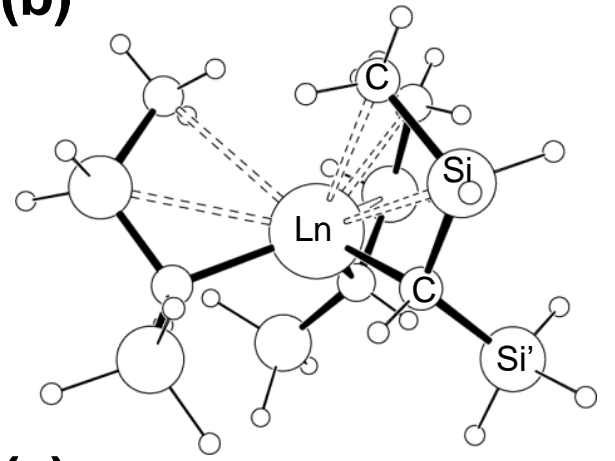

(c)

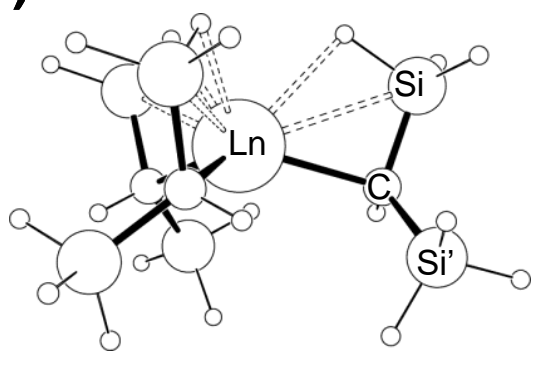


Figure 2

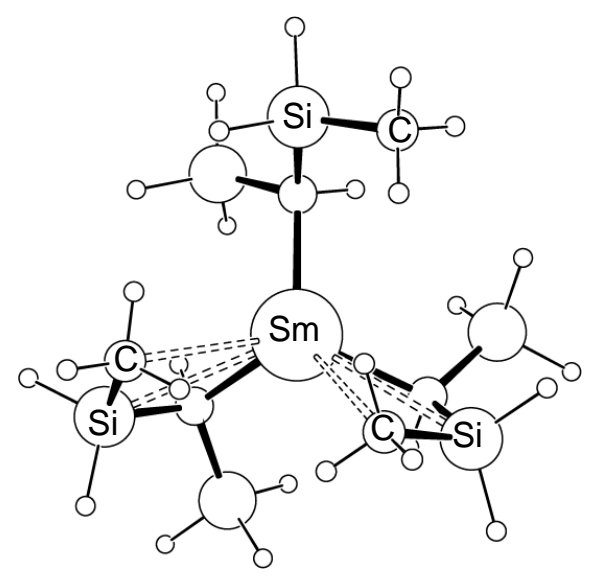


Scheme 1

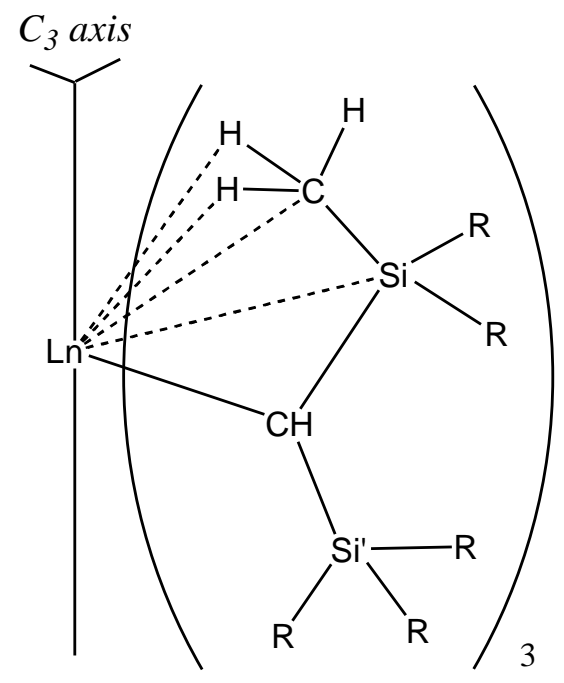

